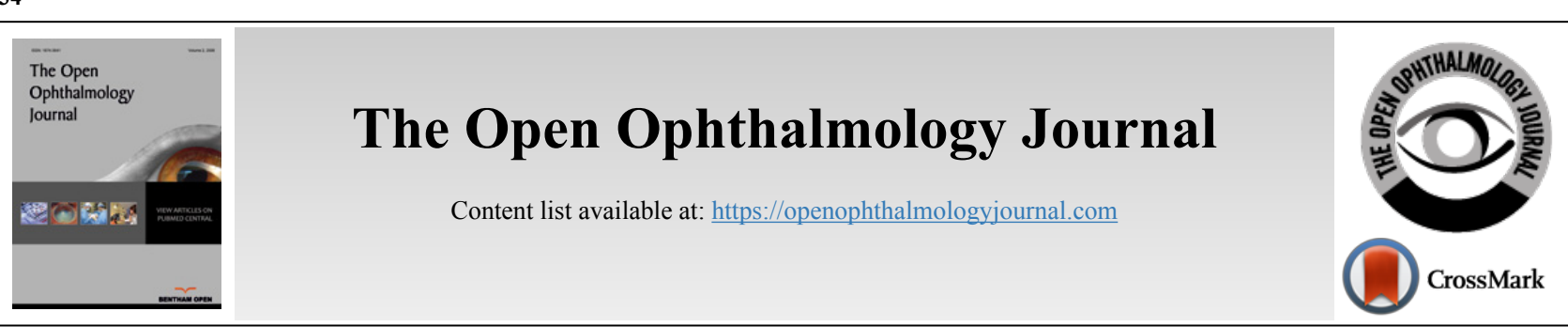

RESEARCH ARTICLE

\title{
Topical Cyclosporine (0.05\%) for Management of Dry Eyes in Patients Undergoing Cataract Surgery-A Comparative Study
}

\author{
Sri Ganesh, Sheetal Brar and Sheetal N. Bagare* \\ Nethradhama Superspeciality Eye Hospital, Bangalore, India
}

\begin{abstract}
:
Purpose:

To assess the efficacy of topical cyclosporine $0.05 \%$ in the management of cataract surgery induced dry eye.

Methods:

This prospective, comparative, randomized, interventional study included 67 patients undergoing cataract surgery. The patients were randomized into three categories Group A: patients on topical lubricants and cyclosporine $0.05 \%$, Group B: patients on topical lubricants only and Group C: patients not on any dry eye medication. Patients were given the respective treatment 2 weeks prior and 3 months after cataract surgery, along with an identical perioperative regimen of topical steroids, antibiotics and NSAIDs. Dry eye evaluation done 2 weeks pre-op, 1 week post-op and 3 months post-op consisted of a subjective questionnaire, tear osmolarity, Tear Break Up Time (TBUT) and Schirmer's 1 without and with anaesthesia.

Results:

Pre-operatively, all the 3 groups were matched in terms of mean age, tear osmolarity, TBUT and Schirmer's 1 without and with anaesthesia scores. At 3 months, patients treated with both topical lubricants and cyclosporine $(0.05 \%)($ Group A) showed improvement subjective questionnaire, tear osmolarity, TBUT and Schirmer's 1 tests. Patients treated with lubricants only (Group B) showed a significant worsening in TBUT and tear osmolarity at 1 week, however, the values returned to baseline at 3 months. The control group (Group C) had the worst TBUT scores at the end of 3 months and showed the persistence of raised tear osmolarity, suggestive of a prolonged ocular inflammation resulting in patient dissatisfaction.

Conclusion:

Topical cyclosporine $(0.05 \%)$ may be a useful adjuvant to prevent and treat cataract surgery associated with dry eye symptoms, especially in patients with pre-existing dry eye disease.
\end{abstract}

Keywords: Cyclosporine, Dry eye, Tear osmolarity, Cataract surgery, Topical Cyclosporine, Tear Break Up Time (TBUT).

\begin{tabular}{|l|l|l|l} 
Article History & Received: December 09, 2018 & Revised: March 21, 2019 & Accepted: April 04, 2019
\end{tabular}

\section{INTRODUCTION}

Various studies have proven that cataract surgery aggravates and causes dry eye and disrupts the normal tear film, whose function is to maintain a healthy ocular surface. Hence, optimization of the ocular surface prior to and after cataract surgery is imperative in such patients. Over recent years, inflammation has been shown to be the key in the pathogenesis of tear film anomalies. Regardless of the triggering factor, a vicious cycle of inflammation consisting of cytokine production, activation of T-lymphocytes further leading to sec-

* Address correspondence to this author at the Nethradhama Superspeciality Eye Hospital, 256/14, Kanakapura main road, $7^{\text {th }}$ block, Jayanagar, Bangalore560082, India; Tel: +91- 9916393219;

Email: sheetalnb15@gmail.com retion of pro-inflammatory cytokines, which may cause tear dysfunction and dry eye $[1,2]$.

Cyclosporine $\mathrm{A}$ is a fungal-derived peptide that inhibits Tcell activation and consequently inhibits the inflammatory cytokine production (selective inhibition of IL-I). In addition, it inhibits apoptosis and increases the density of conjunctival goblet cells [3]. Topical Cyclosporine A has been shown to be effective in various ocular conditions, without any systemic or ocular side effects [4 - 7]. The international task force guidelines for dry eye also recommended the use of cyclosporine A for treatment of dry eye and tear film dysfunction [8].

Various factors have been associated with post cataract surgery dry eye such as the use of topical anesthetics, medica- 
tions containing epitheliotoxic preservatives $[9,10]$, disruption of corneal innervation due to wound creation, concomitant meibomian gland disease and exposure to light from the operating microscope etc. These often lead to symptoms such as foreign body sensation, redness, itching, watering and ocular fatigue after cataract surgery.

Few studies have investigated changes in tear film characteristics and tear osmolarity changes after cataract surgery [11 - 14], however, limited number of studies have evaluated the role of topical cyclosporine $(0.05 \%)$ in the treatment of dry eye following cataract surgery [15].

Hence, the present study was conducted with the purpose of studying tear film osmolarity changes following cataract surgery and investigating the role of topical cyclosporine $(0.05 \%)$ in optimizing the ocular surface and its potential in the treatment of cataract surgery associated dry eye.

\section{MATERIALS AND METHODS}

This prospective, comparative, randomized, interventional study was approved by institutional ethics committee and adhered to the tenets of declaration of Heilsinki. A formal informed consent was obtained from all the patients participating in the study.

\subsection{Study Population}

Patients between the age group of 50-70 years presenting with bilateral cataract, not on any dry eye medication and scheduled to undergo phacoemulsification surgery for age related cataract were included.

\subsection{Exclusion Criteria}

Patients diagnosed to have dry eye and already on treatment, history of refractive or other ocular surgeries, cataract more than Grade 3 of Lens Opacities Classification System2 (LOCS2), disorders of lids such as severe meibomian dysfunction, blepharitis, lagophthalmos, chronic disorders of conjunctiva, cornea, sclera-chronic allergic conditions, conjunctivitis, keratitis, scleritis, episcleritis, contact lens use, chemical burns, radiation injury, herpes zoster ophthalmicus, chronic ocular pathologies and medications for conditions such as glaucoma, uveitis, ocular infections, chronic systemic diseases causing severe recurrent chronic dry eye-connective tissue disorders and patients on immunosuppressive medications were excluded from the study.

\subsection{Methodology}

Sixty seven patients satisfying the inclusion criteria were evaluated for the tear film status clinically and objectively by using the following tests in the following sequence.

[1] Tear lab ${ }^{\mathrm{TM}}$ (Germany) equipment: Tear lab ${ }^{\mathrm{TM}}$ Reader of model number: 200000 REV B; Tear lab ${ }^{\mathrm{TM}}$ Pen of model number: 200001 REV B

Both eyes were tested at the same time, to identify intra-eye difference. The eye with higher osmolarity score was recruited in the study.

[2] Tear Film Break Up Time (TBUT)

[3] Schirmer's test 1 without anaesthesia: Whatmann filter paper $41(5 \times 35 \mathrm{~mm})$ Schirmer's test strip
[4] Schirmer's test 1 with anaesthesia: Whatmann filter paper $41(5 \times 35 \mathrm{~mm})$ Schirmer's test strip with topical anesthesia

All the dry eye tests were performed by a single, independent observer on all visits to rule out any observer bias. Randomization of eyes was performed using computer generated random numbers and based on the treatment regimen prescribed, patients were assigned to either of the following three groups:

Group A (25 eyes): Topical Lubricants (I-Dew DS, 1\% Carboxy Methyl Cellulose, Entod pharmaceuticals, Mumbai, India) 4 times / day + topical cyclosporine (Cyclotears eye drops $0.05 \%$, Entod pharmaceuticals, Mumbai, India) 2 times/day for 2 weeks prior and 3 months post cataract surgery.

Group B (25 eyes): Topical lubricants (I-Dew DS, 1\% Carboxy Methyl Cellulose, Entod pharmaceuticals, Mumbai, India) 4 times / day for 2 weeks prior and 3 months post cataract surgery.

Group C (17 eyes): Control group (No dry eye medication received pre or post-op)

All patients were called for biometric assessment in the week preceding their cataract surgery and after ensuring proper usage of drops as per instructions, they underwent phacoemulsification surgery under topical anesthesia, by a single experienced surgeon. Vancomycin $20 \mu \mathrm{g} / \mathrm{ml}$ was added to the Irrigation fluid-balanced salt solution. No occlusion therapy was used after cataract surgery.

Post-operative regimen was identical to all 3 groups and consisted of Prednisolone acetate 1\% eye drops (Predforte, Alcon Laboratories, U.S.A) 6 times/day, tapering weekly over 6 weeks and Nepafenac eye drops (Nepatop, $0.1 \%$ Nepafenac, Entod pharmaceuticals, Mumbai, India) 3 times/day for 4 weeks and Moxifloxacin $0.5 \%$ eye drop(Vigamox $0.5 \%$, Alcon Laboratories, U.S.A) 4 times/day for 4 weeks. None of the patients reported any side effects following usage of the medications prescribed.

Post-operative follow ups were scheduled on day 1,1 week and 3 months. At $1^{\text {st }}$ week, along with the routine postoperative evaluation, tear film osmolarity, Schirmer's test without and with anaesthesia, and TBUT were performed. At 3 months, subjective questionnaire was also obtained in addition to the $1^{\text {st }}$ week tests [16]. The patients in the control group, were however askedto report anytime, if they develop discomfort or dry eye symptoms in the operated eye.

\subsection{Statistical Analysis}

Data was entered into Microsoft excel data sheet and was analyzed using SPSS 22 version (IBM SPSS Statistics, Somers NY, USA) software. Categorical data was represented in the form of Frequencies and proportions. Chi-square test was used as a test of significance for qualitative data. Continuous data was represented as mean and SD. ANOVA (Analysis of Variance) was the test of significance to identify the mean difference between more than two groups for quantitative data. Paired t test was the test of significance for paired data such as pre op and post op follow up for quantitative data. A p-value of $<0.05$ was considered statistically significant. 


\section{RESULTS}

Table 1 shows the pre-operative demographic and clinical parameters of all the three study groups. There was no significant difference in mean age, gender, eye laterality, tear osmolarity scores, TBUT, Schirmer's 1 test without and with anaesthesia between the three study groups ( $\mathrm{p}$ value $>0.05$ for all parameters).

\subsection{Tear Osmolarity}

Compared to pre, the mean tear osmolarity showed comparable scores at 1 week, across all groups (Table 2). At 3 months, however, the mean tear osmolarity scores were lowest in group $\mathrm{A}$ and highest in group $\mathrm{C}$, and the difference achieved a statistical significance $(\mathrm{p}=0.04)$.

At $1^{\text {st }}$ week, all groups observed worsening in tear osmolarity scores compared to pre, however, the worsening was statistically significant in group B and $C(p=0.001$ for group $B$ and $p=0.021$ for group $C$ ). At the end of 3 months, the mean tear osmolarity scores had improved significantly in group A, compared to 1 week $(\mathrm{p}=0.018)$, whereas the other two groups did not show any significant change (Table 3 , Fig. 1).

In comparison with pre, group A showed improvement, while groups $\mathrm{B}$ and $\mathrm{C}$, showed worsening in mean tear osmolarity scores, the differences were, however, not statistically significant in any group (Table 4).

\subsection{Tear Film Break Up Time (TBUT)}

At $1^{\text {st }}$ week, compared to pre, the mean TBUT scores showed mild reduction in all study groups, the mean scores being comparable ( $p$ - value $>0.05$ ). At 3 months, however, the mean TBUT scores were significantly better for group A compared to the other groups $(\mathrm{p}=0.00)$ (Table 2$)$.

Compared to pre and 1 week, the mean TBUT in group A improved significantly at 3 months $(p=0.023$ and 0.03 respectively). On the contrary, group $\mathrm{C}$ showed a significant worsening in TBUT scores at 3 months compared to both pre $(\mathrm{p}=0.036)$ and $1^{\text {st }}$ week $(\mathrm{p}=0.05)$ scores. Group $\mathrm{B}$, however, did not show any statistically significant variation in the TBUT values at any post-op visit (Tables $3 \& 4$, Fig. 2).

\subsection{Schirmer's 1 Without and With Anaesthesia}

At $1^{\text {st }}$ week and 3 months, the mean Schirmer's test 1 scores were highest in group A compared to the other groups, the difference was however not statistically significant (pvalue $>0.05$ ), (Table 2 ).

In Group A, compared to pre, significant improvement in mean Schirmer's 1 without anaesthesia scores was noted, both at $1^{\text {st }}$ week $(\mathrm{p}=0.04)$ and 3 months post-op $(\mathrm{p}=0.00)$, However, the other two groups did not show a similar trend. The scores improved post-operatively in both B \&C groups, but the difference was not statistically significant (Tables $3 \& 4$, Fig. 3).

On the other hand, the mean Schirmer's 1 with anaesthesia scores did not show significant variation at any post-op visit for any group, except group A where scores were observed to have significantly improved at 3 months, compared to one week post-op scores (p value 0.015) (Tables 3 \& 4, Fig. 4).

\subsection{Subjective Questionnaire}

A subjective questionnaire [16] was obtained from all patients at pre and 3 months post-op visits regarding the various symptoms of dry eye and tolerance to the topical medications. In group A, mean score of subjective questionnaire was significantly better ( $p$-value $=0.031$ ), while in group $\mathrm{C}$, the score was significantly worse compared to pre-op scores ( $p$-value $=0.050$ ). No significant change in mean sub-jective questionnaire scores was observed for group B (Table 4).

None of the patients reported any adverse effects such as redness, itching, stinging sensation, swelling of lids etc., due to the use of cyclosporine eye drops, when prescribed in the preoperative period.

\section{DISCUSSION}

Dry eye associated symptoms frequently occur as a consequence of cataract surgery and can be a major cause of patient dissatisfaction following a perfect cataract surgery. The purpose of the present study was to investigate the role of $0.05 \%$ cyclosporine eye drops in the management of cataract surgery associated dry eye and compare the outcomes with only lubricants or no dry eye medication prescribed in the perioperative period of cataract surgery.

Dry eye post cataract surgery poses a medical challenge to the clinician, as it may either aggravate pre-existing dry eye condition or potentially induce symptoms of dry eye. Patients undergoing cataract surgery already have some tear film abnormalities due to ageing, and hormonal and systemic conditions. Cataract surgery is expected to further worsen the pre-existing dry eye, through various mechanisms described earlier $[9,10$, $12,14,17]$. Hyperosmolarity, which often results from excessive tear evaporation disrupting normal ion concentrations, is a common finding across all forms of dry eye diseases [18]. Increased osmolarity has been shown to cause ocular surface epithelial cell death by initiating apoptosis cascade, cause inflammation and up-regulate inflammatory cytokines [10, 17, 19].

Recently, some studies have highlighted the role of topical cyclosporine $(0.05 \%)$ in the management of conditions associated with surface ocular inflammation including allergic eye diseases, VKC, and dry eye $[4,7,20]$. Few studies have shown its safety and efficacy in treating dry eye associated with cataract surgery. Chung et al evaluated the effectiveness of cyclosporine $0.05 \%$ for dry eye after cataract surgery and they observed a significant improvement in the Schirmers1 and TBUT scores compared to placebo [15].

Studies have shown that onset of action of topical cyclosporine is slow $[21,22]$, hence, $0.05 \%$ cyclosporine drops and lubricants were initiated 2 weeks prior to the scheduled cataract surgery in order to alleviate aggravation of dry eye symptoms immediate post-op. The symptoms of dry eye are expected to peak in the immediate post-operative period of cataract surgery, when the surgery induced inflammation is maximum.

Our results showed that there was worsening of tear osmolarity scores at 1 week post cataract surgery compared to pre, in all groups, reiterating the known fact that cataract surgery induces and aggravates pre-existing dry eye, especially immediate post-op, through various mechanics as suggested by 
previous studies $[1,12,14]$. The worsening of tear osmolarity was statistically significant in groups B and C, however, it was mild and statistically insignificant in group $\mathrm{A}$.

The group $\mathrm{C}$ treated with only post-operative regimen and no dry eye medication, showed worsening tear film break up time and persistence of elevated tear osmolarity, at 3 month follow-up compared to pre and 1 week post-op. This could indicate that not prescribing any medication for ocular surface maintenance, may lead to aggravation of dry eye condition. This also correlated well with the subjective questionnaire obtained at the last follow-up. Since the control group was only on post-operative topical steroids, this may suggest that topical steroids alone may have a limited role in post cataract surgery dry eye. On the other hand, group B although showed worsening of tear osmolarity and TBUT in the early post-operative period at 1 week, however, did not report worsening of symptoms on subjective questionnaire. The tear film parameters also returned to baseline levels (pre) at the end of 3 months, indicating that lubricant therapy was helpful in stabilizing ocular surface and improving the dry eye associated symptoms.

Table 1. Pre-operative baseline and demographic data of the three study groups.

\begin{tabular}{|c|c|c|c|c|}
\hline (Mean \pm SD) & Group A (Cyclosporine A +Lubricant) & Group B (Lubricant) & Group C (Control) & P-Value \\
\hline Mean age(years) & 62.85 .2 & 62.44 .6 & 62.13 .6 & 0.886 \\
\hline M:F ratio & $13: 12$ & $15: 10$ & $5: 12$ & 0.142 \\
\hline Laterality & $10: 15$ & $14: 11$ & $10: 7$ & 0.392 \\
\hline Tear Osmolarity (mOsm/lt) & $303.0 \pm 8.0$ & $299.4 \pm 10.8$ & $303.1 \pm 12.8$ & 0.061 \\
\hline TBUT (sec) & $6.9 \pm 2.5$ & $6.5 \pm 2.3$ & $5.4 \pm 2.9$ & 0.064 \\
\hline Schirmer's 1 without anaesthesia(mm) & $17.4 \pm 8.6$ & $18.2 \pm 8.9$ & $13.4 \pm 7.5$ & 0.341 \\
\hline Schirmer's 1 with anaesthesia (mm) & $15.6 \pm 8.5$ & $14.2 \pm 7.6$ & $16.7 \pm 8.4$ & 0.620 \\
\hline
\end{tabular}

TBUT $=$ Tear film break up time, $\mathrm{SD}=$ Standard deviation

Table 2. Intergroup comparison of mean values of tear osmolarity, TBUT, Schirmers 1 without and with anaesthesia at one week and 3 months post-operative.

\begin{tabular}{|c|c|c|c|c|}
\hline (Mean \pm SD) & Group A (Cyclosporine+ Lubricant) & Group B (Lubricant) & Group C (Control) & P-Value \\
\hline Tear Osmolarity (mOsm/lt) & - & - & - & - \\
\hline Pre & $303.0 \pm 8.0$ & $299.4 \pm 10.8$ & $303.1 \pm 12.8$ & 0.061 \\
\hline 1 week & $305.8 \pm 6.1$ & $309.4 \pm 13.2$ & $310.1 \pm 10.0$ & 0.359 \\
\hline 3 month & $299.3 \pm 10.6$ & $302.8 \pm 13.5$ & $310.1 \pm 14.7$ & 0.041 \\
\hline TBUT (sec) & - & - & - & - \\
\hline Pre & $6.9 \pm 2.5$ & $6.5 \pm 2.3$ & $5.4 \pm 2.9$ & 0.064 \\
\hline 1 week & $6.6 \pm 2.8$ & $6.4 \pm 3.4$ & $5.0 \pm 2.6$ & 0.191 \\
\hline 3 month & $8.7 \pm 3.5$ & $6.1 \pm 2.1$ & $4.4 \pm 2.6$ & 0.00 \\
\hline Pre & - & - & - & - \\
\hline 1 week & $17.4 \pm 8.6$ & $18.2 \pm 8.9$ & $13.4 \pm 7.5$ & 0.341 \\
\hline 3 month & $22.1 \pm 8.4$ & $18.2 \pm 8.5$ & $18.9 \pm 10.9$ & 0.380 \\
\hline Schirmer's 1 without anaesthesia (mm) & $24.2 \pm 9.2$ & $21.7 \pm 9.3$ & $18.8 \pm 11.3$ & 0.292 \\
\hline Pre & - & - & - & - \\
\hline 1 week & $15.6 \pm 8.5$ & $14.2 \pm 7.6$ & $16.7 \pm 8.4$ & 0.620 \\
\hline 3 month & $16.9 \pm 6.9$ & $12.6 \pm 6.6$ & $15.8 \pm 8.9$ & 0.297 \\
\hline
\end{tabular}

TBUT $=$ Tear film break up time, $\mathrm{SD}=$ Standard Deviation

Table 3. Intragroup comparison of mean values of tear osmolarity, TBUT, Schirmers 1 without and with anaesthesia at one week and 3 months post-operative.

\begin{tabular}{|c|c|c|c|c|c|c|c|c|c|}
\hline$($ Mean \pm SD) & \multicolumn{3}{|c|}{$\begin{array}{c}\text { Group A } \\
\text { (Cyclosporine+ Lubricant) }\end{array}$} & \multicolumn{3}{|c|}{$\begin{array}{c}\text { Group B } \\
\text { (Lubricant) }\end{array}$} & \multicolumn{3}{|c|}{$\begin{array}{l}\text { Group C } \\
\text { (Control) }\end{array}$} \\
\hline- & Pre & 1 week & 3 months & Pre & 1 week & 3 months & Pre & 1 week & 3 months \\
\hline $\begin{array}{l}\text { Tear osmolarity } \\
(\mathrm{mOsm} / \mathrm{Lt})\end{array}$ & $303.0 \pm 8.0$ & $305.8 \pm 6.1$ & $299.3 \pm 10.6$ & $299.4 \pm 10.8$ & $309.4 \pm 13.2$ & $302.8 \pm 13.5$ & $303.1 \pm 12.8$ & $310.1 \pm 10.0$ & $310.1 \pm 14.7$ \\
\hline p-value & \multicolumn{2}{|c|}{0.063} & 0.018 & \multicolumn{2}{|c|}{0.001} & 0.076 & \multicolumn{2}{|c|}{0.021} & 0.988 \\
\hline TBUT (sec) & $6.9 \pm 2.5$ & $6.6 \pm 2.8$ & $8.7 \pm 3.5$ & $6.5 \pm 2.3$ & $6.4 \pm 3.4$ & $6.1 \pm 2.1$ & $5.4 \pm 2.9$ & $5.0 \pm 2.6$ & $4.4 \pm 2.6$ \\
\hline
\end{tabular}


(Table 3) contd.....

\begin{tabular}{|c|c|c|c|c|c|c|c|c|c|}
\hline \multirow{2}{*}{ 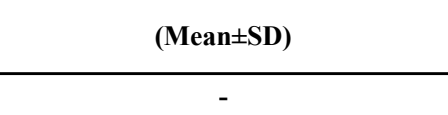 } & \multicolumn{3}{|c|}{$\begin{array}{c}\text { Group A } \\
\text { (Cyclosporine+ Lubricant) }\end{array}$} & \multicolumn{3}{|c|}{$\begin{array}{c}\text { Group B } \\
\text { (Lubricant) }\end{array}$} & \multicolumn{3}{|c|}{$\begin{array}{l}\text { Group C } \\
\text { (Control) }\end{array}$} \\
\hline & Pre & 1 week & 3 months & Pre & 1 week & 3 months & Pre & 1 week & 3 months \\
\hline p-value & \multicolumn{2}{|c|}{0.87} & 0.03 & \multicolumn{2}{|c|}{0.113} & 0.508 & \multicolumn{2}{|c|}{0.36} & 0.05 \\
\hline Schirmer's 1 without anaesthesia $(\mathrm{mm})$ & $17.4 \pm 8.6$ & $22.1 \pm 8.4$ & $24.2 \pm 9.2$ & $18.2 \pm 8.9$ & $18.2 \pm 8.5$ & $21.7 \pm 9.3$ & $13.4 \pm 7.5$ & $18.9 \pm 10.9$ & $18.8 \pm 11.3$ \\
\hline p-value & \multicolumn{2}{|c|}{0.04} & 0.087 & \multicolumn{2}{|c|}{0.58} & 0.369 & \multicolumn{2}{|c|}{0.55} & 0.57 \\
\hline $\begin{array}{c}\text { Schirmer's } 1 \text { with anaesthesia } \\
(\mathrm{mm})\end{array}$ & $15.6 \pm 8.5$ & $16.9 \pm 6.9$ & $19.2 \pm 9.0$ & $14.2 \pm 7.6$ & $12.6 \pm 6.6$ & $15.8 \pm 8.8$ & $16.7 \pm 8.4$ & $15.8 \pm 8.9$ & $15.4 \pm 10.9$ \\
\hline p-value & \multicolumn{2}{|c|}{0.91} & 0.015 & \multicolumn{2}{|c|}{0.73} & 0.130 & \multicolumn{2}{|c|}{0.45} & 0.83 \\
\hline
\end{tabular}

TBUT= Tear film break up time, $\mathrm{SD}=$ Standard Deviation

Table 4. Intragroup comparison of mean values of tear osmolarity, TBUT, Schirmers 1 without and with anaesthesia between pre and 3 months post-operative.

\begin{tabular}{|c|c|c|c|c|c|c|}
\hline \multirow{2}{*}{$\frac{(\text { Mean } \pm \text { SD })}{-}$} & \multicolumn{2}{|c|}{$\begin{array}{c}\text { Group A } \\
\text { (Cyclosporine+Lubricant) }\end{array}$} & \multicolumn{2}{|c|}{$\begin{array}{c}\text { Group B } \\
\text { (Lubricant) }\end{array}$} & \multicolumn{2}{|c|}{$\begin{array}{l}\text { Group C } \\
\text { (Control) }\end{array}$} \\
\hline & Pre & 3 months & Pre & 3 months & Pre & 3 months \\
\hline Tear osmolarity(mosm/lt) & $303.0 \pm 8.0$ & $299.3 \pm 10.6$ & $299.4 \pm 10.8$ & $302.8 \pm 13.5$ & $303.1 \pm 12.8$ & $310.1 \pm 14.7$ \\
\hline p-value & \multicolumn{2}{|c|}{0.256} & \multicolumn{2}{|c|}{0.364} & \multicolumn{2}{|c|}{0.876} \\
\hline TBUT (sec) & $6.9 \pm 2.5$ & $8.7 \pm 3.5$ & $6.5 \pm 2.3$ & $6.1 \pm 2.1$ & $5.4 \pm 2.9$ & $4.4 \pm 2.6$ \\
\hline p-value & \multicolumn{2}{|c|}{0.023} & \multicolumn{2}{|c|}{0.226} & \multicolumn{2}{|c|}{0.036} \\
\hline Schirmer's 1 without anaesthesia $(\mathrm{mm})$ & $17.4 \pm 8.6$ & $24.2 \pm 9.2$ & $18.2 \pm 8.9$ & $21.7 \pm 9.3$ & $13.4 \pm 7.5$ & $18.8 \pm 11.3$ \\
\hline p-value & \multicolumn{2}{|c|}{0.004} & \multicolumn{2}{|c|}{0.909} & \multicolumn{2}{|c|}{0.431} \\
\hline $\begin{array}{c}\text { Schirmer's } 1 \text { with anaesthesia } \\
(\mathrm{mm})\end{array}$ & $15.6 \pm 8.5$ & $19.2 \pm 9.0$ & $14.2 \pm 7.6$ & $15.8 \pm 8.8$ & $16.7 \pm 8.4$ & $15.4 \pm 10.9$ \\
\hline p-value & \multicolumn{2}{|c|}{0.068} & \multicolumn{2}{|c|}{0.198} & \multicolumn{2}{|c|}{0.313} \\
\hline $\begin{array}{l}\text { Subjective Questionnaire } \\
\text { (Total score }=24)\end{array}$ & $11.41 \pm 2.2$ & $8.35 \pm 2.15$ & $10.08 \pm 1.20$ & $10.61 \pm 2.14$ & $11.70 \pm 1.40$ & $14.50 \pm 2.20$ \\
\hline p-value & \multicolumn{2}{|c|}{0.031} & \multicolumn{2}{|c|}{0.451} & \multicolumn{2}{|c|}{0.050} \\
\hline
\end{tabular}

TBUT $=$ Tear film break up time, $\mathrm{SD}=$ standard deviation

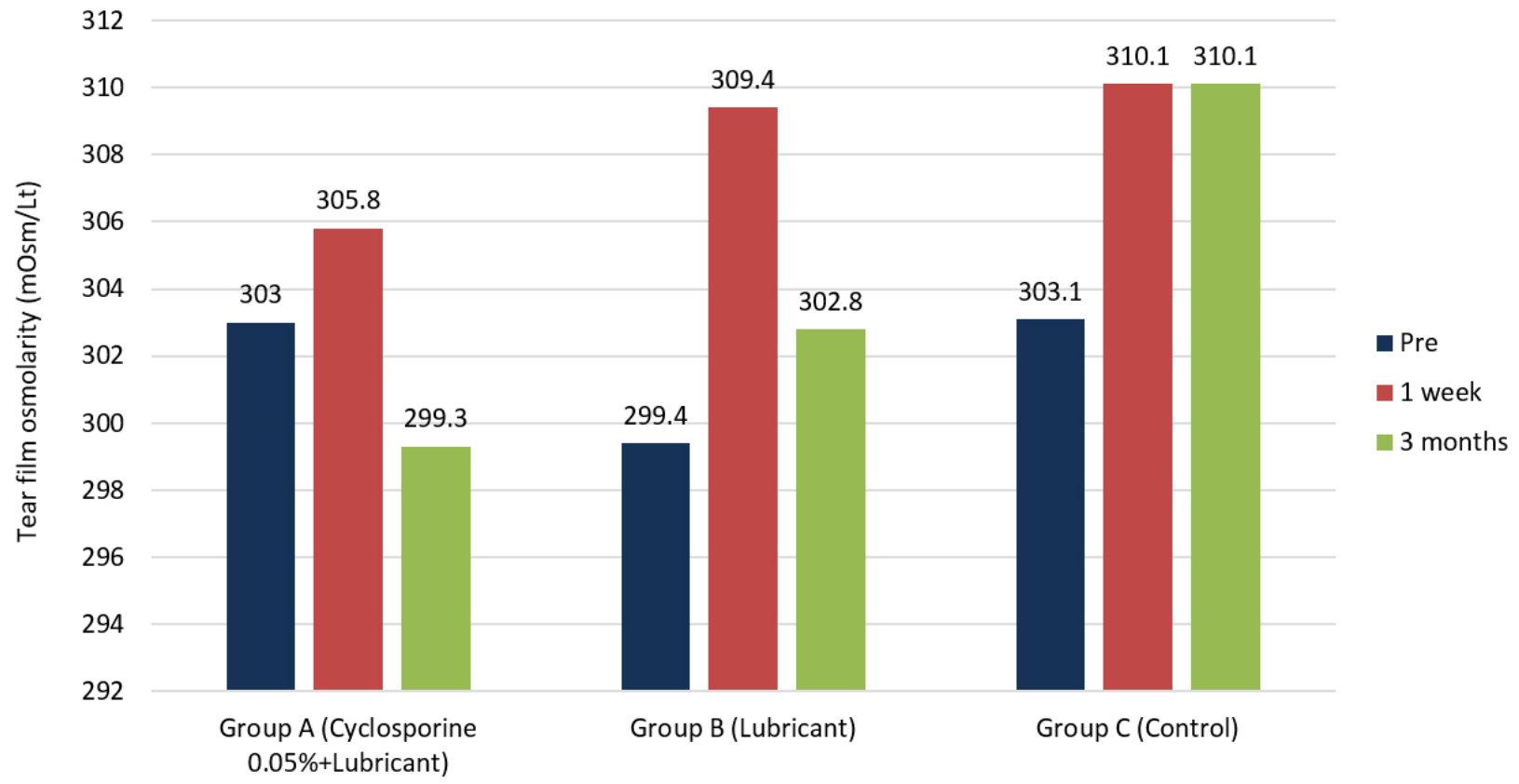

Fig. (1). Tear osmolarity at pre, 1 week and 3 months post op follow up. 


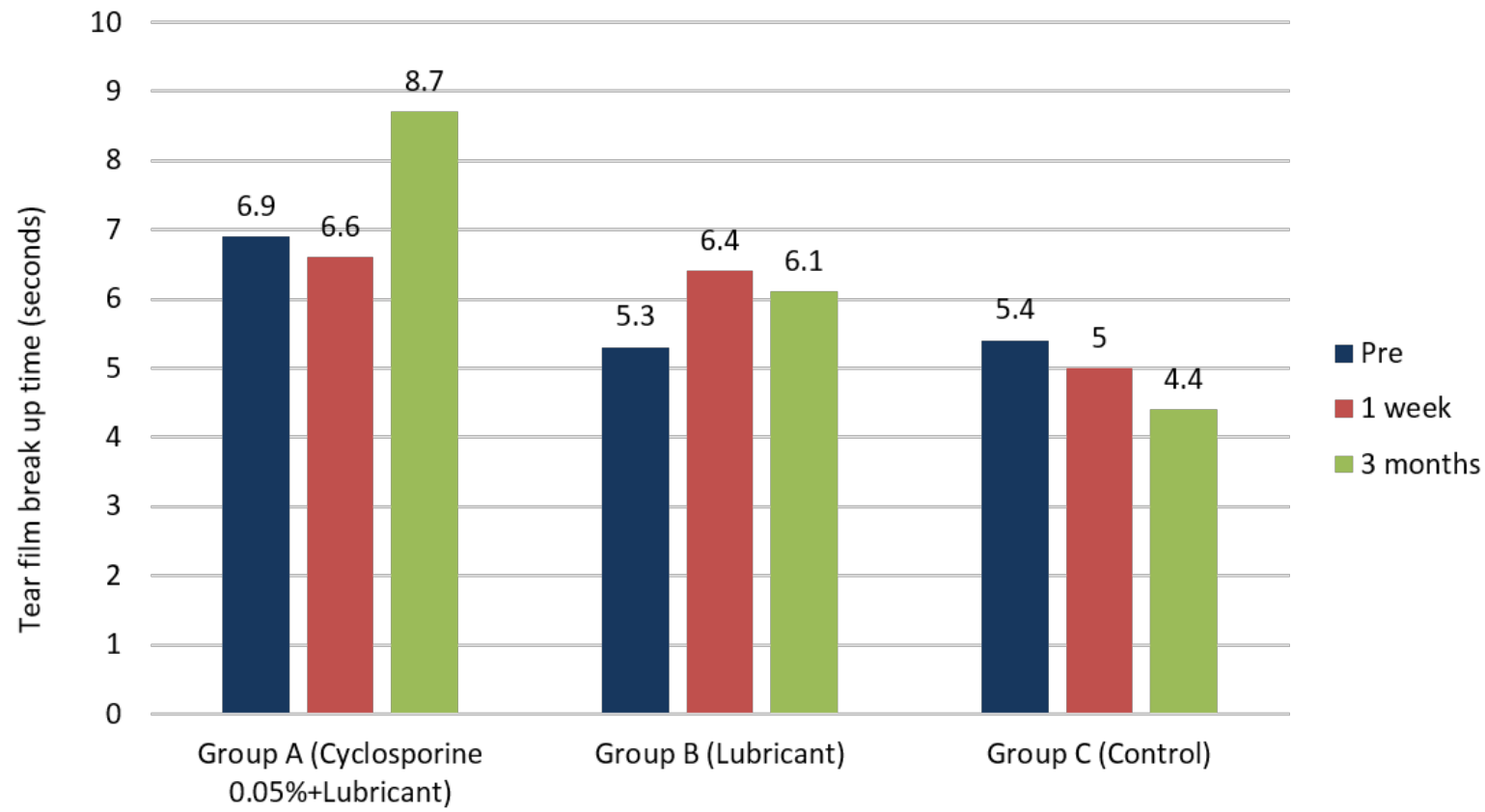

Fig. (2). Tear film break up time(TBUT) scores at pre op, 1 week and 3 months post op follow up.

$$
30
$$

25 24.2

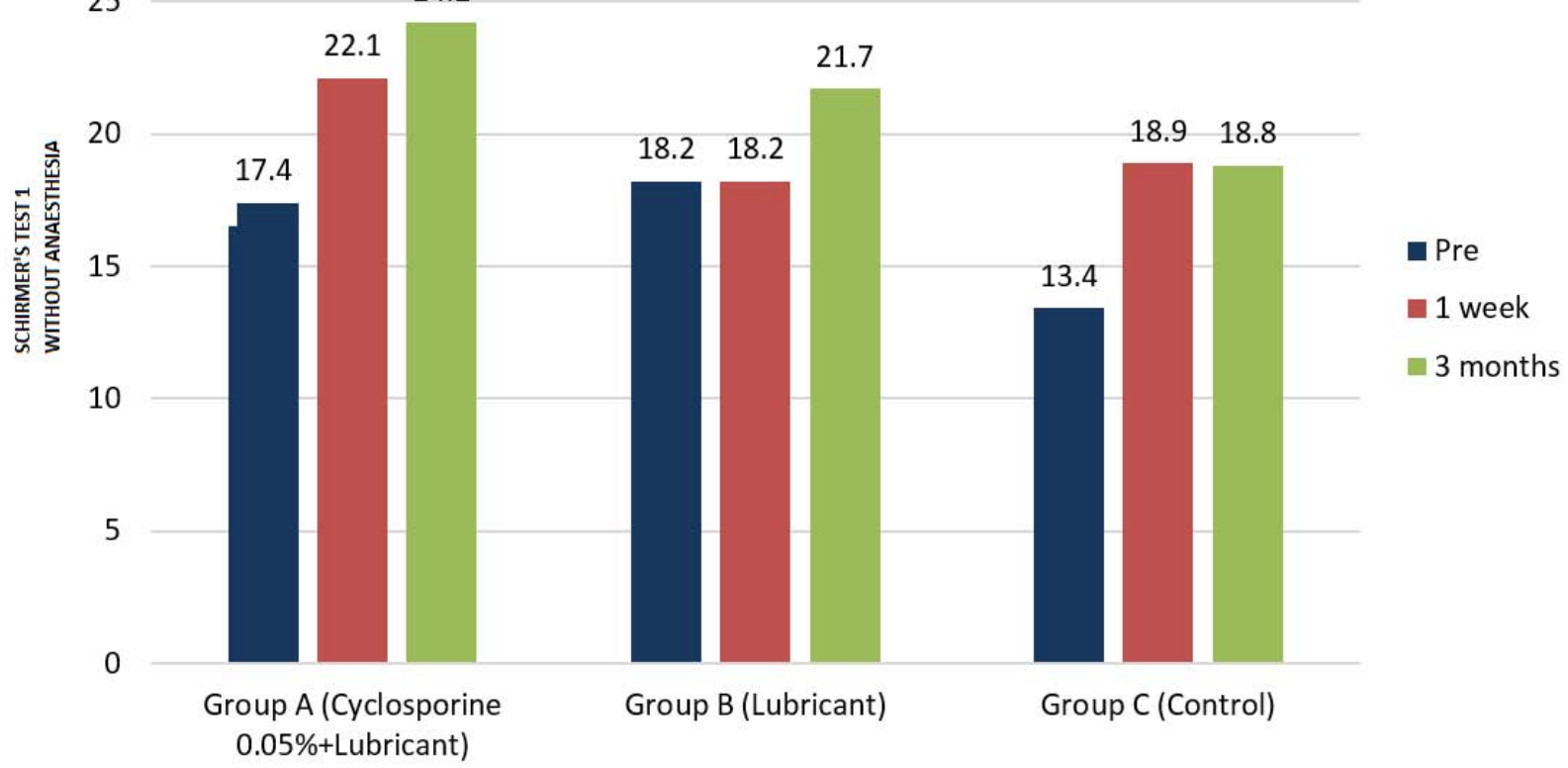

Fig. (3). Schirmer's 1 without anaesthesia scores at pre op, 1 week and 3 months post op follow up. 


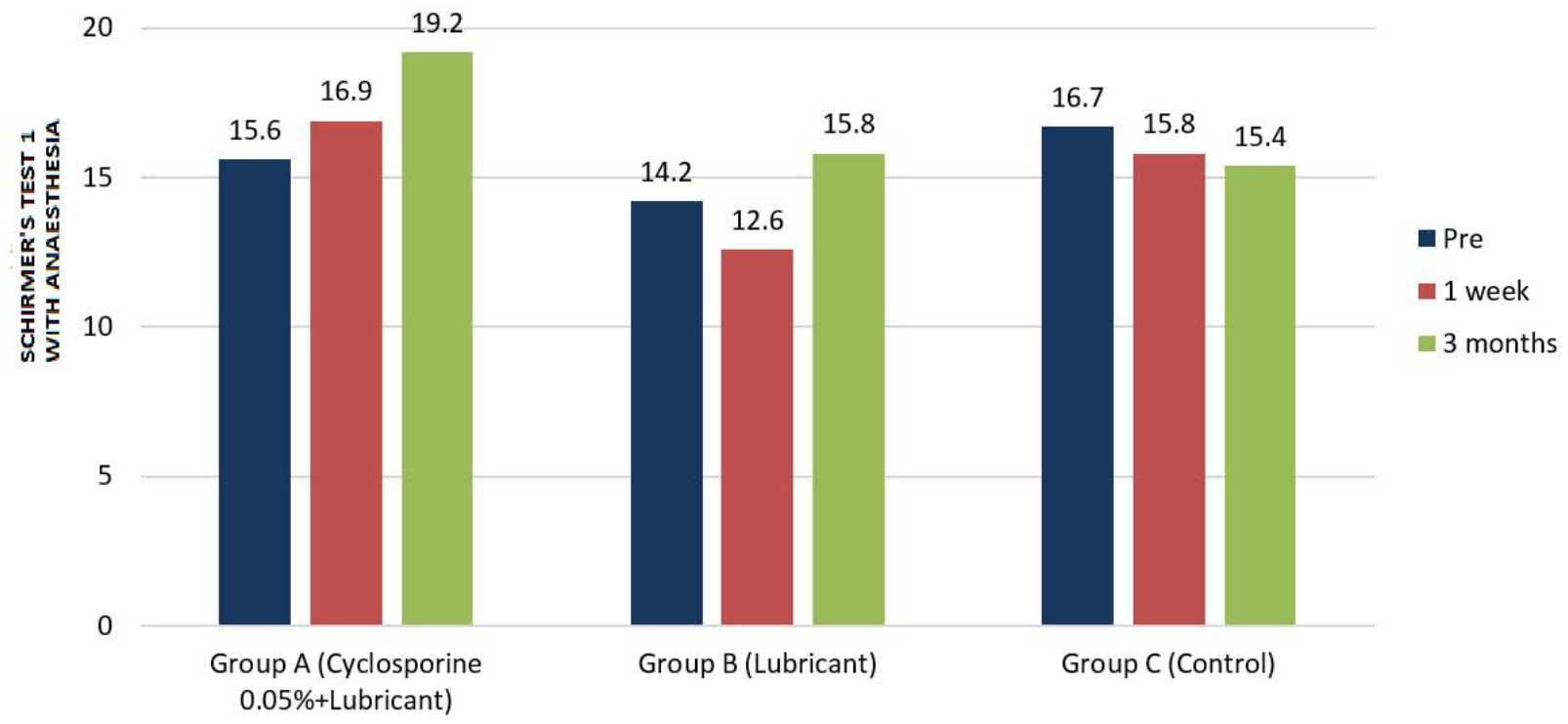

Fig. (4). Schirmer's 1 with anaesthesia scores at pre op, 1 week and 3 months post op follow up.

However, in group A all clinical parameters such as tear osmolarity, TBUT and Schirmer's tests were found have improved, at the last follow-up when compared to pre-op. The TBUT scores and Schirmers 1 test scores were significantly better at 3 months, indicating more favourable outcome in terms of tear film stability and both reflex and basal tear secretion compared to the other two groups. Subjectively also, patient reported better comfort at 3 months even when compared to pre-op, which was statistically significant. This could probably suggest that the combination therapy of cyclosporine with lubricant may be superior in controlling surgery induced inflammation, when compared to only lubricants for maintenance of ocular surface in peri-operative period of cataract surgery.

We included tear osmolarity as one of the test parameters in this study, as recent studies have suggested tear osmolarity as the most reliable and objective test for dry eye evaluation. Tomilson et al found that tear hyperosmolarity, defined by a referent of $316 \mathrm{mOsmol} / \mathrm{L}$, was superior in overall accuracy to any other single test for dry eye diagnosis [23]. A recent review by Potvin et al. also showed that literature broadly supports the use of tear film osmolarity as an objective numerical measure for diagnosing, grading severity, and managing treatment of DED [24].

The results of our study may be more relevant in the setting of premium IOL implantation, where many studies have reported that pre-existing dry eye may adversely affect the keratometry measurements before surgery and is also an important cause of patient dissatisfaction after surgery, due to poor quality of vision [25]. Donnenfeld et al. also showed that Cyclosporine $0.05 \%$ therapy was effective in reducing dry eye signs and improved visual quality after multifocal IOL implantation [26, 27].
Potential limitations of our study were relatively small sample size and simultaneous administration of $0.05 \%$ topical cyclosporine A, along with topical antibiotics, steroids, and NSAIDs in the post-operative period for the first 6 weeks. However, since the design of the study was such that the effect of cyclosporine was to be studied in the scenario of cataract surgery, post-operative regimen consisting of above mentioned medications could not have been avoided. The 1st week follow up parameters are more likely to be altered by the steroid regimen. However, steroids were uniformly tapered over 6 weeks in all the three groups, after 6 weeks only study drugs ie topical lubricants and cyclosporine $0.05 \%$ were continued until the end of 3 months. Therefore, 3 -month parameter is a more reliable indicator of variations in the tear film characteristics. Finally, this study was an open-label study using commercial eye drops due to which subjective factors cannot be excluded. The absence of blindness might affect the study results.

Based on the results of our study, we recommend that topical lubricants must be an integral part of the post-operative regimen after cataract surgery. Regarding the routine use of topical cyclosporine $(0.05 \%)$ as an adjuvant to lubricants, it may be stated that since the drug has a proven safety profile, there is no contraindication of its use in the peri-operative period of cataract surgery. In the pre-operative period, this would stabilize the surface to achieve a more accurate biometry and thus better post-operative refractive result. In the postoperative period, this would help to relieve the post-op dryness induced due to inflammation, meibomitis and post-op medications such as topical steroids and NSAIDs. Although this would increase the cost of the therapy, however, would result in better ocular comfort and patient satisfaction. 


\section{CONCLUSION}

In conclusion, topical lubricant and cyclosporine combination therapy in the perioperative period may provide better maintenance of the ocular surface health and homeostasis reflected by improvement in the tear film parameters and alleviation of subjective symptoms. Hence, the routine use of topical Cyclosporine $0.05 \%$ as an adjuvant in the management of post-operative dry eye is recommended provided the drug is well tolerated and there are no concerns regarding affordability. However, future prospective clinical trials are suggested to verify our results and evaluate the long term safety and efficacy of topical cyclosporine in this scenario.

\section{LIST OF ABBREVIATIONS}

$$
\begin{array}{ll}
\text { TBUT } & =\text { Tear Break Up Time } \\
\text { LOCS2 } & =\text { Lens Opacities Classification System2 }
\end{array}
$$

\section{ETHICS APPROVAL AND CONSENT TO PARTI- CIPATE}

This prospective, comparative, randomized, interventional study was approved by institutional ethics committee and adhered to the tenets of declaration of Heilsinki. A formal informed consent was obtained from all the patients participating in the study.

\section{HUMAN AND ANIMAL RIGHTS}

No Animals were used in this research. All human research procedures followed were in accordance with the ethical standards of the committee responsible for human experimentation (institutional and national), and with the Helsinki Declaration of 1975, as revised in 2013.

\section{CONSENT FOR PUBLICATION}

Not applicable.

\section{FUNDING}

None.

\section{CONFLICT OF INTEREST}

The author declares no conflict of interest, financial or otherwise.

\section{ACKNOWLEDGEMENTS}

Declared none.

\section{SUPPLEMENTARY MATERIAL}

Supplementary material is available on the publishers web site along with the published article.

\section{REFERENCES}

[1] Mircheff AK, Gierow JP, Yang T, et al. Sjögren's autoimmunity: How perturbation of recognition in endomembrane traffic may provoke pathological recognition at the cell surface. J Mol Recognit 1998; 11(1-6): 40-8.

[http://dx.doi.org/10.1002/(SICI)1099-1352(199812)11:1/6<40::AID-J MR387>3.0.CO;2-X] [PMID: 10076804]

[2] Gao J, Schwalb TA, Addeo JV, Ghosn CR, Stern ME. The role of apoptosis in the pathogenesis of canine keratoconjunctivitis sicca: The effect of topical Cyclosporin A therapy. Cornea 1998; 17(6): 654-63. [http://dx.doi.org/10.1097/00003226-199811000-00014] [PMID: 982 0947]

[3] Kunert KS, Tisdale AS, Gipson IK. Goblet cell numbers and epithelial proliferation in the conjunctiva of patients with dry eye syndrome treated with cyclosporine. Arch Ophthalmol 2002; 120(3): 330-7. [http://dx.doi.org/10.1001/archopht.120.3.330] [PMID: 11879137]

[4] Kiliç A, Gürler B. Topical 2\% cyclosporine A in preservative-free artificial tears for the treatment of vernal keratoconjunctivitis. Can J Ophthalmol 2006; 41(6): 693-8.

[http://dx.doi.org/10.3129/i06-061] [PMID: 17224949]

[5] Liegner JT, Yee RW, Wild JH. Topical cyclosporine therapy for ulcerative keratitis associated with rheumatoid arthritis. Am J Ophthalmol 1990; 109(5): 610-2.

[http://dx.doi.org/10.1016/S0002-9394(14)70704-4] [PMID: 2333932]

[6] Turan-Vural E, Torun-Acar B, Kivanc SA, Acar S. The effect of topical $0.05 \%$ cyclosporine on recurrence following pterygium surgery. Clin Ophthalmol 2011; 5: 881-5.

[http://dx.doi.org/10.2147/OPTH.S19469] [PMID: 21760716]

[7] Perry HD, Doshi-Carnevale S, Donnenfeld ED, Solomon R, Biser SA, Bloom AH. Efficacy of commercially available topical cyclosporine A $0.05 \%$ in the treatment of meibomian gland dysfunction. Cornea 2006; 25(2): 171-5.

[http://dx.doi.org/10.1097/01.ico.0000176611.88579.0a] [PMID: 1637 1776]

[8] Behrens A, Doyle JJ, Stern L, et al. Dysfunctional tear syndrome: A Delphi approach to treatment recommendations. Cornea 2006; 25(8): 900-7.

[http://dx.doi.org/10.1097/01.ico.0000214802.40313.fa] [PMID: 1710 2664]

[9] Daneshwar R, Zaidi F, Eds. Cataract surgery and dry eye, Cataract Surgery. 4th ed. IntechOpen 2013.https://www.intechopen.com/books /cataract-surgey/cataract-surgery-and-dry-eye

[10] Luo L, Li DQ, Doshi A, Farley W, Corrales RM, Pflugfelder SC. Experimental dry eye stimulates production of inflammatory cytokines and MMP-9 and activates MAPK signaling pathways on the ocular surface. Invest Ophthalmol Vis Sci 2004; 45(12): 4293-301. [http://dx.doi.org/10.1167/iovs.03-1145] [PMID: 15557435]

[11] Sinha M, Sinha A, Chowdhury B. Comparative Evaluation of Dry Eye following Cataract Surgery: A Study from North India. IOSR Journal of Dental and Medical Sciences 2014; 13(6): 13-8.

[http://dx.doi.org/10.9790/0853-13631318]

[12] Cho YK, Kim MS. Dry eye after cataract surgery and associated intraoperative risk factors. Korean J Ophthalmol 2009; 23(2): 65-73. [http://dx.doi.org/10.3341/kjo.2009.23.2.65] [PMID: 19568353]

[13] Kasetsuwan N, Satitpitakul V, Changul T, Jariyakosol S. Incidence and pattern of dry eye after cataract surgery. PLoS One 2013; 8(11)e78657

[http://dx.doi.org/10.1371/journal.pone.0078657] [PMID: 24265705]

[14] Dodia K, Bapat S, Chudasama RK. Dry eye risk factors after phacoemulsification cataract surgery at a secondary care hospital. Int $\mathrm{J}$ Health Allied Sci 2013; 2: 242-5.

[http://dx.doi.org/10.4103/2278-344X.126711]

[15] Chung YW, Oh TH, Chung SK. The effect of topical cyclosporine $0.05 \%$ on dry eye after cataract surgery. Korean J Ophthalmol 2013; 27(3): 167-71.

[http://dx.doi.org/10.3341/kjo.2013.27.3.167] [PMID: 23730108]

[16] Schein OD, Tielsch JM, Munõz B, Bandeen-Roche K, West S Relation between signs and symptoms of dry eye in the elderly. A population-based perspective. Ophthalmology 1997; 104(9): 1395-401.

[http://dx.doi.org/10.1016/S0161-6420(97)30125-0] [PMID: 9307632]

[17] Li XM, Hu L, Hu J, Wang W. Investigation of dry eye disease and analysis of the pathogenic factors in patients after cataract surgery. Cornea 2007; 26(9)(Suppl. 1): S16-20.

[http://dx.doi.org/10.1097/ICO.0b013e31812f67ca] [PMID: 1788 1910]

[18] Baudouin C, Aragona P, Messmer EM, et al. Role of hyperosmolarity in the pathogenesis and management of dry eye disease: Proceedings of the OCEAN group meeting. Ocul Surf 2013; 11(4): 246-58. [http://dx.doi.org/10.1016/j.jtos.2013.07.003] [PMID: 2411 2228]

[19] Stevenson W, Chauhan SK, Dana R. Dry eye disease: An immunemediated ocular surface disorder. Arch Ophthalmol 2012; 130(1): 90-100.

[http://dx.doi.org/10.1001/archophthalmol.2011.364] [PMID: 2223 2476]

[20] Perry HD, Doshi-Carnevale S, Donnenfeld ED, Solomon R, Biser SA, 
Bloom AH. Efficacy of commercially available topical cyclosporine A $0.05 \%$ in the treatment of meibomian gland dysfunction. Cornea 2006; 25(2): 171-5.

[http://dx.doi.org/10.1097/01.ico.0000176611.88579.0a] [PMID: 16371776]

[21] Byun YS, Rho CR, Cho K, Choi JA, Na KS, Joo CK. Cyclosporine $0.05 \%$ ophthalmic emulsion for dry eye in Korea: A prospective, multicenter, open-label, surveillance study. Korean J Ophthalmol 2011; 25(6): 369-74.

[http://dx.doi.org/10.3341/kjo.2011.25.6.369] [PMID: 22131772]

[22] Chung YW, Oh TH, Chung SK. The effect of topical cyclosporine $0.05 \%$ on dry eye after cataract surgery. Korean J Ophthalmol 2013; 27(3): 167-71.

[http://dx.doi.org/10.3341/kjo.2013.27.3.167] [PMID: 23730108]

[23] Tomlinson A, Khanal S, Ramaesh K, Diaper C, McFadyen A. Tear film osmolarity: Determination of a referent for dry eye diagnosis. Invest Ophthalmol Vis Sci 2006; 47(10): 4309-15. [http://dx.doi.org/10.1167/iovs.05-1504] [PMID: 17003420]

[24] Potvin R, Makari S, Rapuano CJ. Tear film osmolarity and dry eye disease: A review of the literature. Clin Ophthalmol 2015; 9: 2039-47. [http://dx.doi.org/10.2147/OPTH.S95242] [PMID: 26586933]

[25] Epitropoulos AT, Matossian C, Berdy GJ, Malhotra RP, Potvin R. Effect of tear osmolarity on repeatability of keratometry for cataract surgery planning. J Cataract Refract Surg 2015; 41(8): 1672-7. [http://dx.doi.org/10.1016/j.jcrs.2015.01.016] [PMID: 26432124]

[26] Donnenfeld ED, Solomon R, Roberts CW, Wittpenn JR, McDonald MB, Perry HD. Cyclosporine $0.05 \%$ to improve visual outcomes after multifocal intraocular lens implantation. J Cataract Refract Surg 2010; 36(7): 1095-100.

[http://dx.doi.org/10.1016/j.jcrs.2009.12.049] [PMID: 20610085]

[27] Chuang J, Shih KC, Chan TC, Wan KH, Jhanji V, Tong L. Preoperative optimization of ocular surface disease before cataract surgery. J Cataract Refract Surg 2017; 43(12): 1596-607. [http://dx.doi.org/10.1016/j.jcrs.2017.10.033] [PMID: 29335106]

(C) 2019 Ganesh et al.

This is an open access article distributed under the terms of the Creative Commons Attribution 4.0 International Public License (CC-BY 4.0), a copy of which is available at: (https://creativecommons.org/licenses/by/4.0/legalcode). This license permits unrestricted use, distribution, and reproduction in any medium, provided the original author and source are credited. 